\title{
Khaled Gawdat, M.D.
}

\author{
Khaled Gawdat ${ }^{1}$
}

Published online: 16 April 2018

(C) Springer Science+Business Media, LLC, part of Springer Nature 2018

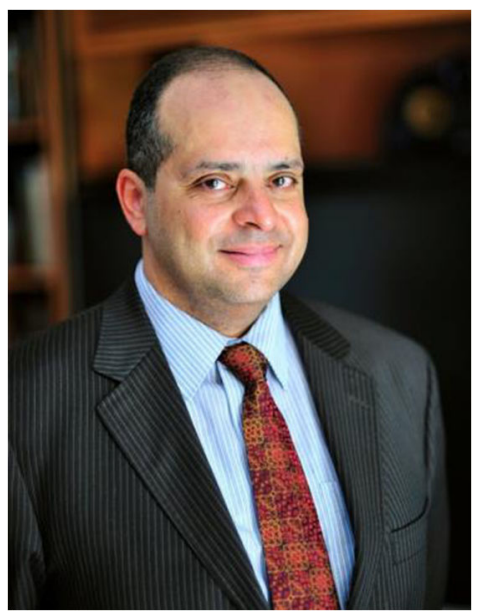

tions, and publications have influenced the practice of many bariatric surgeons in the Middle East region.

Khaled Gawdat graduated in 1985 from Ain-Shams School of Medicine in Cairo, Egypt. After graduation, he completed a general surgery residency at Ain Shams School of Medicine followed by a 2-year general surgery residency in St. Elizabeth Hospital in Boston, Massachusetts, USA. Dr. Gawdat also received a short fellowship at the Lahey Clinic, Burlington, Massachusetts, USA, before returning to Egypt.

Dr. Gawdat received a Master degree in general surgery in 1989 and a PhD in general surgery in 1992 . He is currently a professor of surgery at Ain-Shams School of Medicine. He started his 22-year bariatric surgery career in 1996. He has performed more than 3500 bariatric procedures, he has presented papers in most IFSO meetings, and he has participated in postgraduate courses and performed live surgery in Austria, India,

Khaled Gawdat, MD, is a pioneer in bariatric surgery in Egypt China, and UAE. His main research interests in bariatric surgery are revisional bariatric surgery, management of complications, and long-term outcomes in different bariatric procedures.

Khaled Gawdat led the development of bariatric surgery in Egypt and the Middle East by bringing together the initial bariatric surgeons to establish the Egyptian Society for Bariatric Surgery (ESBS) in 1999 that later represented Egypt in the IFSO and he was the ESBS president from 1999 to 2009 . The society helped promote bariatric surgery in the region through 13 annual conferences, training courses, live surgery seminars, and postgraduate courses. He also helped in establishing the Pan Arab Society for Metabolic and Bariatric Surgery PASMBS and was elected the first president in 2016. Through his efforts for a unified regional presence, the IFSO approved the formation of the IFSO Middle East and North African chapter (IFSO MENA) and he was elected the member at large and IFSO executive board member in 2017. He was a member of the Editorial board for Obesity Surgery journal 2002-2011.

Other than bariatric surgery, Khaled Gawdat is an Avid award winning photographer and for him photography is a hobby, a passion, and a way to make a moment immortal. 